Miembro del Comité Editorial AMC, Inmunóloga pediatra, Universidad de Costa Rica. Hospital Nacional de Niños "Dr. Carlos Sáenz Herrera". Caja Costarricense de Seguro Social.
El Ángulo del Investigador

\section{Elementos básicos de bioética en investigación}

\author{
Olga Arguedas-Arguedas
}

La Dra. Adriana Rojas, Jefe de Residentes de Pediatría del Hospital Nacional de Niños "Dr. Carlos Sáenz Herrera", nos pregunta: ¿Requieren los estudios retrospectivos basados en registros médicos una evaluación desde el punto de vista bioético igual a la de los ensayos clínicos controlados?

Iniciamos la respuesta con un rotundo NO, para evitar dudas al lector. La mayor parte de las consideraciones bioéticas y las derivaciones regulatorias consecuentes han sido pensadas para el manejo apropiado de los estudios de investigación que tienen un diseño experimental, llamados también estudios intervencionales, que incluyen a los ensayos clínicos controlados con medicamentos, vacunas e implementos médicos, así como otras intervenciones de naturaleza biopsicosocial.

Los estudios de ciencias básicas que se realizan con animales de laboratorio u otros sustratos de la naturaleza tienen algunas consideraciones bioéticas particulares, que serán motivo de un futuro comentario en esta sección. Un ámbito interesante y diferente, que requiere consideraciones bioéticas muy singulares lo constituyen los estudios genéticos.

Los estudios basados en registros médicos, listas de pacientes, bases de datos, material de archivo, deben cumplir con las normas básicas de poseer solidez científica, respetar principios de autoría, y aspectos de confidencialidad. Sin embargo, ninguno de los instrumentos normativos relacionados con la ética en investigación biomédica, llámense Código de Nüremberg, Declaración de Helsinki, Guías de Buena Práctica Clínica de la Conferencia Internacional de Armonización, Guías Internacionales de Ética para investigación biomédica que involucra seres humanos del Consejo de Organizaciones Internacionales de Ciencias Médicas (CIOMS) etc, han sido diseñados para el ámbito de la investigación descriptiva.

En la mayor parte de los países con un desarrollo bioético y científico importante, los estudios descriptivos son usualmente sometidos a revisiones de "forma" de carácter académico y a procesos simplificados de inscripción, que tienen el propósito de evitar la duplicidad de las investigaciones, conflictos de autoría y de garantizar la solidez científica de los mismos.

En nuestro país, a nivel de la Caja Costarricense del Seguro Social, la revisión y aprobación de propuestas de investigación de carácter descriptivo recae sobre los Comités Locales de Bioética en Investigación (CLOBI), en tanto que la regulación de las propuestas para estudios intervencionales debe ser realizada en el Comité Institucional de Bioética en Investigación (COIBI). Existen otros comités acreditados por el Consejo Nacional de Investigación en Salud (CONIS) del Ministerio de Salud, para la regulación de estudios intervencionales que se efectúan fuera de los servicios asistenciales de la Caja Costarricense del Seguro Social. A la fecha, la situación de los comités acreditados para evaluar, y dar seguimiento a estudios intervencionales, es poco clara, dado un reciente fallo emitido a este respecto por nuestra Sala Constitucional.

Los estudios intervencionales requieren siempre de una evaluación bioética rigurosa antes de su ejecución, por parte de un Comité Ético Científico independiente, que garantice que en el desarrollo de los mismos se respetan los principios básicos de la ética en investigación biomédica: autonomía, beneficencia, no maleficencia y justicia. A partir de estos principios se han construido 
múltiples códigos, guías, declaraciones, reglamentaciones y normativas, por lo que considero de suma importancia que todo profesional en ciencias de la salud tenga al menos una idea básica de los mismos.

Estos principios o juicios prescriptivos generales son de mucha utilidad para que tanto los investigadores, como participantes, revisores, autoridades de salud y ciudadanos interesados comprendan mejor los aspectos éticos inherentes a la investigación que involucra seres humanos. A continuación trato de ofrecer una explicación lo más sencilla y concreta posible de dichos principios.

\section{Principio de autonomía}

El principio ético de autonomía se refiere al respeto por los derechos de cada persona a tomar sus propias decisiones. En el campo de la investigación clínica, el principio de autonomía se concreta con la obtención de un consentimiento informado, comprensivo, competente y voluntario de la persona que va a participar en una investigación. El proceso de consentimiento en investigación clínica, es un ejercicio de elección inteligente que hace la persona basada en información suficiente y comprensible.

En términos generales, el consentimiento informado es obligatorio, siempre que vaya a existir algún tipo de intervención biomédica o psicosocial en el individuo, que pueda variar el desenlace de un fenómeno dado y/o siempre que vaya a existir un contacto prospectivo entre el investigador y la persona, para efectos propios de la investigación. Es deseable, que los comités de ética de la investigación en cada centro o país, suministren a los investigadores una guía de los aspectos básicos que deben incluirse en formulario de consentimiento informado.

\section{Principio de beneficencia/ No maleficencia}

Este principio debe entenderse como la obligación de no hacer daño a las personas que participan en una investigación, en el terreno práctico tratando de maximizar todos los posibles beneficios y previendo las acciones necesarias para minimizar los eventuales riesgos. En la correcta aplicación del principio de beneficencia en la vida práctica, es de máxima relevancia la evaluación riesgo/beneficio que de manera obligatoria debe hacer un comité ético-científico independiente basado en la revisión del protocolo de investigación antes de su ejecución.

El comité de ética de la investigación debe asegurarse de identificar los potenciales riesgos del estudio y de que existen todas las medidas necesarias para minimizarlos. También debe reconocer los potenciales beneficios para los participantes, y que existen las medidas para incrementarlos en lo posible. En una tercera dimensión debe también evaluar que los potenciales beneficios para pacientes futuros y para la sociedad, son proporcionales o sobrepasan los riesgos del estudio.

\section{Principio de Justicia}

Este principio se fundamenta en la equidad de la distribución de los riesgos y beneficios de la investigación.

La aplicación concreta del principio de justicia tiene que ver directamente con los criterios de selección de las personas que van a participar en una investigación, en dos niveles: individual y social. La justicia individual en la selección de los participantes, implica que el investigador es equitativo en ofrecer a cada persona las mismas posibilidades de riesgo o beneficio, independientemente de su condición social, étnica o de género.

La aplicación del principio de justicia en el nivel social se refiere a la distinción que debe hacerse de grupos de personas particularmente vulnerables como prisioneros, enfermos mentales, minorías étnicas, niños, mujeres embarazadas, enfermos terminales, en los cuáles los estudios de investigación deben conducirse solamente en situaciones seleccionadas.

Estas poblaciones vulnerables, dado su status de dependencia o su capacidad comprometida para consentir libremente, deben ser protegidas del peligro de ser involucrados en estudios de investigación, por el solo hecho de conveniencia administrativa o porque son fáciles de manipular como resultado de su enfermedad o condición socio-económica.

La aplicación del principio de justicia en el nivel social ha sido motivo de una intensa transformación en las últimas décadas, ya que la exclusión de ciertas poblaciones de estudios de investigación tales como niños, mujeres embarazadas y algunas minorías étnicas, ha generado un efecto negativo para ellas, ya que no se genera la información médica necesaria para la aplicación de muchos avances terapéuticos en esos grupos particulares.

Partiendo de estos tres principios básicos, a comienzos del presente siglo, se establecieron siete criterios que se consideran ampliamente como necesarios y suficientes para que la investigación biomédica sea éticamente correcta.

Dichos criterios son:

1. Valor social de la investigación

2. Validez científica

3. Selección justa de los participantes

4. Relación favorable de Riesgo/beneficio

5. Revisión Independiente

6. Consentimiento informado

7. Respeto por los participantes en un estudio de investigación. 


\section{Comentario final}

La historia de la experimentación médica y las reglas que la gobiernan han tenido una profunda y constante transformación en los últimos 150 años. Mucho tiempo de discusión y análisis se ha invertido en las décadas pasadas para refinar y modificar, las ideas de lo que es correcto y respetuoso con la humanidad en el ámbito de la investigación científica, de acuerdo a las demandas de los tiempos y al creciente acceso del ser humano a nuevas tecnologías.

La investigación biomédica es la piedra angular que ha permitido la construcción de grandes avances en todas las áreas de la medicina, y en esta era del conocimiento basado en evidencia, no se puede concebir la práctica de la medicina contemporánea sin una vigorosa actividad paralela de investigación clínica. Sin embargo, múltiples incidentes lamentables, trágicos y vergonzosos han acaecido en el desarrollo de la investigación biomédica en el último siglo. Forman parte de esta oscura página de la investigación biomédica, los experimentos nazis en los campos de concentración, los estudios de Tuskegee, Willowbrook, la tragedia de la Talidomida, los estudios con antiretrovirales en Africa Subsahariana y muchos otros. Gran diversidad de asuntos conexos con la investigación clínica, como lo son muertes trágicas, incentivos económicos desproporcionados, relaciones intrincadas entre instituciones públicas y la industria farmaceútica, y la realización de ensayos clínicos controlados en países en vías en desarrollo han generado la existencia de grupos de personas con ideas radicales en sentidos diversos, sobre este tema.

En nuestro país, existe una enorme confusión respecto a la pertinencia de la evaluación y vigilancia de aspectos bioéticos, en diferentes tipos de investigación. Desafortunadamente, a la fecha, un fenómeno común es el de extrapolar los altos y complejos estándares de evaluación bioética que requieren los estudios intervencionales a todo tipo de estudio, lo cuál es, no solo ilógico y desproporcionado, sino también una pérdida de tiempo y de recursos. 